\title{
Risk factors associated with hypertensive disorders in pregnancy in Nekemte referral hospital, from July 2015 to June 2017, Ethiopia: case-control study
}

Leta Hinkosa ${ }^{1 *}$, Almaz Tamene ${ }^{2+}$ and Negeso Gebeyehu ${ }^{3+}$

\begin{abstract}
Background: Hypertension is the most common medical problem encountered in pregnancy and is a leading cause of perinatal and maternal morbidity and mortality. However, its magnitude and risk factors yet not adequately assessed at the study area.

Methods: Facility-based retrospective unmatched case-control study was conducted to identify risk factors associated with Hypertensive disorders of pregnancy in Nekemte Referral Hospital just two years back from study period July 1, 2015, to June 30, 2017. Bivariate logistic regression was considered for inclusion in to the multivariate logistic regression. Finally, multi varaite analysis were done to identify risk factors of hypertensive disorders of pregnancy.

Results: Among 6826 total delivery records from July 2015 -June 2017, 199 women developed hypertension during pregnancy. Among 199 women 153(76.9\%) were pre-eclampsia/eclampsia,28(14.1\%) were gestational hypertension, 14(0.7\%) were superimposed hypertension and 4 (2.9\%) were chronic hypertension.

Age $\geq 35$ (AOR: 2.51, 95\% Cl: 1.08, 5.83), rural residential area (AOR: 1.79, 95\% Cl: 1.150, 2.799), prim gravida (AOR: 3.39, 95\% Cl: 2.16, 5.33), null parity (AOR: 4.35, 95\% Cl: 2.36, 8.03), positive history of abortion (AOR: 4.39, 95\% Cl: 1.64, 11.76), twin pregnancy (AOR: 3.78, 95\% Cl: 1.52, 9.39), lack of ANC follow up (AOR: 3.05, 95\% Cl: 1.56, 5.96) as well as positive pre-existing hypertension (AOR: 3.81, 95\% Cl: 1.69, 8.58), positive family history of hypertension (AOR: 5.04 , $95 \% \mathrm{Cl}: 2.66,9.56)$ and positive history of diabetes mellitus (AOR: $5.03,95 \% \mathrm{Cl}: 1.59,15.89$ ) were risk factors for hypertensive disorders during pregnancy.

Conclusion: This study found that Women with hypertension during pregnancy have a greater risk of developing adverse pregnancy outcome as compared to normotensive pregnant women. so, identification of these risk factors would be useful for early diagnosis of hypertension disorders during pregnancy to give appropriate clinical monitoring and treatments and timely managing maternal and perinatal complications.
\end{abstract}

Keywords: Risk factors, Hypertension disorders, Pregnancy

\footnotetext{
* Correspondence: leta.hinko43@gmail.com

${ }^{1}$ Department of Midwifery, Institute of Health Sciences, Wollega University,

Nekemte, Ethiopia

Full list of author information is available at the end of the article
}

(c) The Author(s). 2020 Open Access This article is distributed under the terms of the Creative Commons Attribution 4.0 International License (http://creativecommons.org/licenses/by/4.0/), which permits unrestricted use, distribution, and reproduction in any medium, provided you give appropriate credit to the original author(s) and the source, provide a link to the Creative Commons license, and indicate if changes were made. The Creative Commons Public Domain Dedication waiver (http://creativecommons.org/publicdomain/zero/1.0/) applies to the data made available in this article, unless otherwise stated. 


\section{Background}

Hypertension is a clinical term used to describe high blood pressure [1, 2]. Hypertension in pregnancy is defined as: "Systolic blood pressure greater than or equal to $140 \mathrm{mmHg}$ and/or diastolic blood pressure greater than or equal to $90 \mathrm{mmHg}$ which usually confirmed within four hours apart measurement" [2].

Hypertension disorder of pregnancy encompasses a spectrum of conditions including pre-existing hypertension, gestational hypertension, preeclampsia/eclampsia, and superimposed hypertension.

These conditions range from a mild increase in blood pressure at term with no additional signs or symptoms to severe complications with potential for significant maternal, fetal and neonatal harm [3]. Globally, a significant number of women die every year from pregnancyrelated causes and more than half of these deaths occur in sub-Saharan Africa [4]. Approximately $12 \%$ of the maternal deaths are associated with hypertensive disorders in pregnancy such as pregnancy-induced hypertension $[1-4$,$] . For that reason, hypertension complications are$ among the main public health issues worldwide.

A Hospital-based cross-sectional study conducted in Jimma University Specialized Hospital in Ethiopia showed that the overall prevalence of hypertensive disorders of pregnancy was $8.5 \%$ of which severe preeclampsia and eclampsia accounted for 51.9 and $23.4 \%$, respectively [5]. Moreover, the study done in Debre Brehan Referral Hospital indicated that among 8626 pregnant women who obtained delivery services, $340(3.9 \%)$ of them had hypertensive disorders with an increasing trend from $1.8 \%$ in 2011 to $5.7 \%$ in 2014 [6].

On the other hand, though in Ethiopia, the efforts have been done to identify the risk factors of hypertension and to overcome its effect, its prevalence and risk factors were increasing in the country. The study area population was found in the western part of the country. The study area was the place where the population was highly affected by hypertension disorders during pregnancy. Besides, there is a scarcity of study conducted on risk factors associated with HDP in Nekemte Referral Hospital.

Therefore, it is essential to undertake this study to determine the risk factors and its complications both on mothers and on new-borne in the Hospital.

\section{Methods}

The facility-based retrospective case-control study was conducted to identify risk factors associated with hypertensive disorders of pregnancy in Nekemte Referral Hospital from July 1, 2015, to June 30, 2017.

\section{Source population}

All mothers who delivered in Nekemte Referral hospital.

\section{Study population}

Case group

Cards of mothers who gave birth in Nekemte referral hospital from of July 2015 to June 2017 and found to have hypertensive disorders during pregnancy.

\section{Control group}

Cards of mothers who gave birth in the hospital and not identified to have hypertensive disorders during pregnancy.

\section{Sample size determination}

The sample size was determined on the assumptions of the ratios of $1: 2$, (cases to controls) power $80 \%$, alpha value $95 \%$, and odd ratio 2 by considering relevant factors from other studies that have significant association with hypertension [7-9, and].

From Table 1, The final sample size was taken from diabetes by adding $10 \%$ for incomplete record reviews for the control group since it is the maximum for case (243) and for control (534) the total sample size was 777.

\section{Sampling technique and procedure}

Among 6826 records of pregnant mothers who gave birth in the study areas, from July 2015 to June 2017 were first sorted for hypertension and without hypertension. Then, based on 1:2 ratios of samples of cases and controls, respectively, 534 (including 10\% for incomplete records) normotensive deliveries were randomly selected.

Out of 777 selected records, 44 cases and 136 controls were excluded from analysis for incomplete of the necessary information. The final data of the study were collected from 199 (81.9\%) cases and 398 (74.5\%) controls which adds to up 597 women by inclusion criteria.

\section{Variables of the study}

A. Dependent variable: Hypertensive disorder of pregnancy.

\section{$B$. Independent variables.}

Demographic variables: Age, Residential area, Marital status, Plan of pregnancy.

Obstetric factors: Gravida. Parity. Abortion history, ANC follow up, Multiplicity of pregnancy.

Medical Disease factors: Pre-existing hypertension, Family history of hypertension. History of diabetes mellitus.

\section{Data collection}

Data was collected from record review using a structured and pre-tested checklist. The training was given for both data collectors and supervisors. Three midwives were assigned to collect the data, one supervisor was assigned to supervise the quality data collection. 
Table 1 Sample size determination

\begin{tabular}{llllll}
\hline Relevant factors & Expected frequency of exposure among control & OR & Case & Control & Total Sample \\
\hline Diabetes & $9 \%$ & 2.4 & 243 & 485 & 728 \\
Prime gravid & $28.08 \%$ & $2.1-3$ & 116 & 232 & 348 \\
Age (> 35 years old) & $31.3 \%$ & 4.5 & 136 & 272 & 408 \\
\hline
\end{tabular}

\section{Data analysis procedures}

Records that shows hypertension during pregnancy were taken as case group and the remaining registries were taken as a control group. Then, to identify the sample and control group, the medical record was retrieved and checked for hypertension during pregnancy.

Accordingly, records that show one of the four of HDP types (gestational hypertension, chronic hypertension, pre-eclampsia/ eclampsia or superimposed hypertension) were taken as case group first and then from the remaining registries control group was randomly obtained.

The criteria were an elevation of blood pressure for gestational hypertension whereas blood pressure, protein urea and other laboratory investigations were used as a criterion for other types of hypertensive disorders. Then finally descriptive statics and logistic regression were used. Descriptive statistics such as frequency, a measure of central tendency and measure of dispersion where were calculated to describe the study sample and presented with tables and figures. To determine factors that were significantly associated with hypertension, the first bivariate logistic regression was done. Then, multiple logistic analysis was performed for those variables identified as significant on bivariate analysis.

\section{Results}

Among 6826 of the total delivery records during the study period, 243 (3.56\%) women had HDP. Of 777 selected records, 44 cases and 136 controls were excluded from analysis for incomplete of necessary information. The final data of the study were collected from 199 (81.9\%) of cases and 398 (74.5\%) of controls which adds to up 597 women.

\section{Demographic characteristics of women with and without HDP}

The mean age of cases was 26.1(SD: \pm 6.1 ) which was higher than that of the controls 24.4(SD: \pm 4.9 ). Eightysix $(43.2 \%)$ of the cases and $218(54.8 \%)$ of the controls were below the age of 25 years whereas $28(14.1 \%)$ of the cases and 19(4.8\%) of the controls were above the age of 35 years (Table 2 ).

\section{Medical disease history of women with and without HDP}

Concerning to medical disease factors, $35(17.6 \%)$ of cases and $15(3.8 \%)$ of controls had positive pre-existing hypertension whereas $164(82.4 \%)$ of cases and $383(96.2 \%)$ of controls had not pre-existing hypertension.

\section{Obstetric history characteristics of women with and without HDP}

Among study participants, 109 (54.8\%) of the case group and $102(25.6 \%)$ of the control group were identified for prim gravida while $90(45.2 \%)$ cases and $296(74.4 \%)$ of controls were of multigravida pregnancies (Table 3). Regarding parity, $64(32.2 \%)$ of cases and $24(6.0 \%)$ of controls were found to be nulliparous whereas $135(67.8 \%)$ of cases and $374(94.0 \%)$ controls were of parity greater or equal to 1 . The parity difference between two groups was significant $\left(\chi^{2}(1, n=597)=70.02, p=.00\right.$, phi $\left.=-.35\right)$.

As it showed in Fig. 1: there were 153 (76.9\%) preeclampsia/ eclampsia, 28 (14.1\%) gestational hypertension, $14(7.0 \%)$ superimposed hypertension, and $4(2.0 \%)$ chronic hypertension (Fig. 1).

Table 2 Demographic characteristics of women with and without Hypertension disorders of pregnancy attended delivery service in the year July 2015-June 2017

\begin{tabular}{lllll}
\hline Variables & $\begin{array}{l}\text { Case } \\
\text { Number (\%) }\end{array}$ & $\begin{array}{l}\text { Control } \\
\text { Number (\%) }\end{array}$ & $X^{2}$ & $P$-value \\
\hline $\begin{array}{clll}\text { Age category } \\
25-29\end{array}$ & $54(27.1)$ & $113(28.4)$ & 19.36 & .000 \\
$<25$ & $86(43.2)$ & $218(54.8)$ & & \\
$30-34$ & $31(15.6)$ & $48(12.1)$ & & \\
$>34$ & $28(14.1)$ & $19(4.8)$ & & \\
Mean (SD) & $26.1(6.1)$ & $24.4(4.9)$ & & \\
Residence & & & & \\
Urban & $70(35.2)$ & $183(46.0)$ & 5.91 & \\
Rural & $129(64.8)$ & $215(54.0)$ & & .011 \\
Marital status & & & & \\
Single & $22(11.1)$ & $20(5.0)$ & 6.48 & \\
Married & $177(88.9)$ & $378(95.0)$ & & \\
Pregnancy plan & & & & \\
Wanted & $179(89.9)$ & $374(94.0)$ & 2.58 & \\
Unwanted & $20(10.1)$ & $24(6.0)$ & & \\
\hline
\end{tabular}


Table 3 Obstetric history of women with and without Hypertension disorders attended for delivery service in the year July 2015-June 2017

\begin{tabular}{|c|c|c|c|c|}
\hline \multirow[t]{2}{*}{ Variables } & Case & Control & \multirow[t]{2}{*}{$x^{2}$} & \multirow[t]{2}{*}{ P-value } \\
\hline & Number (\%) & Number (\%) & & \\
\hline \multicolumn{5}{|c|}{ Current pregnancy history: Gravida } \\
\hline Prim gravida & $109(54.8)$ & $102(25.6)$ & \multirow[t]{2}{*}{48.05} & \multirow[t]{2}{*}{.000} \\
\hline Multigravida & $90(45.2)$ & $296(74.4)$ & & \\
\hline \multicolumn{5}{|c|}{ Current pregnancy history: Parity } \\
\hline Null parity & $64(32.2)$ & $24(6.0)$ & \multirow[t]{2}{*}{70.02} & \multirow[t]{2}{*}{.000} \\
\hline Parity $>$ or $=1$ & $135(67.8)$ & $374(94.0)$ & & \\
\hline \multicolumn{5}{|c|}{ Current pregnancy history: Abortion } \\
\hline No & $166(83.4)$ & $390(98.0)$ & \multirow[t]{2}{*}{41.80} & \multirow[t]{2}{*}{.000} \\
\hline Yes & $33(16.6)$ & $8(2.0)$ & & \\
\hline \multicolumn{5}{|c|}{ Multiplicity of pregnancy } \\
\hline Single & $181(91.0)$ & $384(96.5)$ & \multirow[t]{2}{*}{6.94} & \multirow[t]{2}{*}{.008} \\
\hline Twin/Multiple & $18(9.0)$ & $14(3.5)$ & & \\
\hline \multicolumn{5}{|c|}{ ANC follow up history } \\
\hline No & $40(20.1)$ & $23(5.8)$ & \multirow[t]{2}{*}{27.33} & \multirow[t]{2}{*}{.000} \\
\hline Yes & $159(79.9)$ & $375(94.2)$ & & \\
\hline
\end{tabular}

Multivariate analysis of risk factors for women with and without HDP

The multivariate analysis revealed that, the age category of 35 years and above (AOR: 2.51, 95\% CI: 1.08, 5.83), rural dwellers (AOR: 1.79, 95\% CI: 1.15, 2.80), prim gravida pregnancies (AOR: 3.39, 95\% CI: 2.16, 5.33),null parity (AOR: 4.35, 95\% CI: 2.36, 8.03),women who had positive history of abortion (AOR: 4.39, 95\% CI: 1.64, 11.76),Twin pregnancies (AOR: 3.78, 95\% CI: 1.52, 9.39), ANC follow up (AOR: 3.05, 95\% CI: 1.56, 5.96), positive pre-existing history of hypertension (AOR: 3.81, 95\% CI: 1.69, 8.58), family history of hypertension (AOR: 5.04, 95\% CI: 2.66, 9.56) History of diabetes mellitus (AOR: 5.03 , 95\% CI: $1.59,15.89)$ were risk factors for hypertension disorders during pregnancy (Table 4).

\section{Differences in maternal outcomes between women with} and without HDP

Regarding the onset of labor, induced labor or $\mathrm{C} / \mathrm{S}$ $108(54.3 \%)$ for cases and 48(12.1\%) controls. The difference of onset of labor between those with and without HDP groups was significant $\left(\chi^{2}(1, n=597)=123.50\right.$, $p=.000$, phi $=.46)($ Table 5$)$.

Normal and instrumental deliveries were higher among controls $(60.8 \%)$ and $(44.2 \%)$ than cases $(29.9 \%)$ and $(16.1 \%)$ respectively.

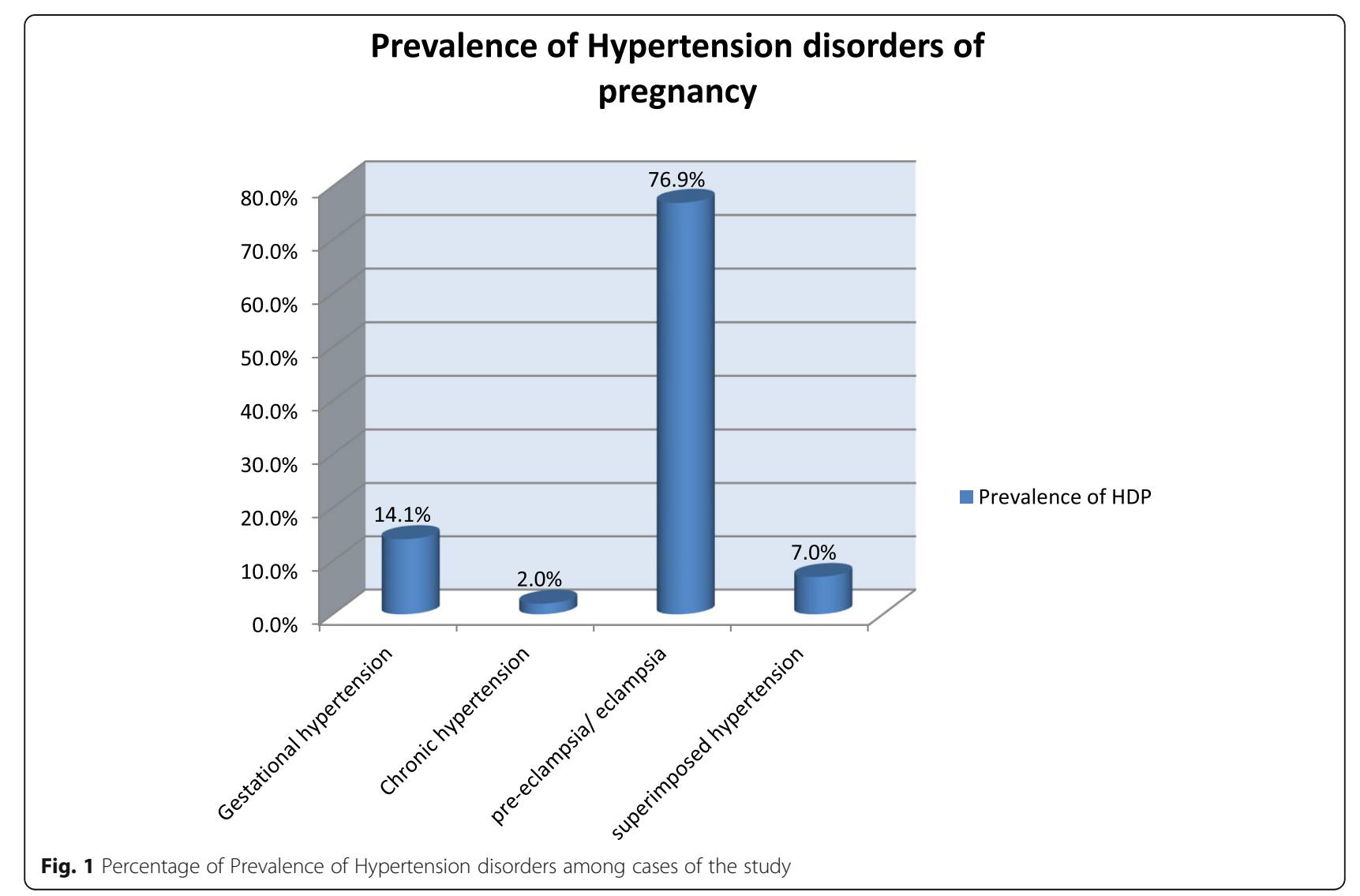


Table 4 Multivariate analysis of risk factors for mothers attended delivery services in July 2015-June 2017

\begin{tabular}{|c|c|c|c|c|}
\hline \multirow[t]{2}{*}{ Variables } & Case & Control & COR (95\%: Cl) & AOR (95\%:Cl) \\
\hline & Number (\%) & \multicolumn{3}{|l|}{ Number (\%) } \\
\hline \multicolumn{5}{|l|}{ Age category } \\
\hline $25-29$ & $54(27.1) 86(43.2)$ & $113(28.4)$ & 1 & 1 \\
\hline$<25$ & $31(15.6)$ & $218(54.8)$ & $.826(.548,1.243)$ & $.744(.446,1.240)$ \\
\hline $30-34$ & $28(14.1)$ & $48(12.1)$ & $1.351(.775,2.356)$ & $1.020(.513,2.026)$ \\
\hline$>34$ & & $19(4.8)$ & $3.084(1.583,6.007)^{* *}$ & $2.508(1.078,5.832) *$ \\
\hline \multicolumn{5}{|l|}{ Residential } \\
\hline Urban & $70(35.2) 129(64.8)$ & $183(46.0) 215$ (54.0) & 1 & 1 \\
\hline Rural & & & $1.569(1.104,2.229) *$ & $1.794(1.150,2.799) *$ \\
\hline \multicolumn{5}{|l|}{ Marital status } \\
\hline Single & $22(11.1)$ & $20(5.0)$ & $2.349(1.250,4.417)^{* *}$ & $1.400(.588,3.330)$ \\
\hline Married & $177(88.9)$ & $378(95.0)$ & 1 & 1 \\
\hline \multicolumn{5}{|l|}{ Gravida } \\
\hline Prim gravida & $109(54.8)$ & $102(25.6)$ & $3.515(2.456,5.030) * *$ & $3.392(2.159,5.330) * *$ \\
\hline Multigravida & $90(45.2)$ & $296(74.4)$ & 1 & 1 \\
\hline \multicolumn{5}{|l|}{ Parity } \\
\hline Null parity & $64(32.2)$ & $24(6.0)$ & $7.388(4.442,12.287) * *$ & $4.349(2.355,8.032) * *$ \\
\hline Parity $>$ or $=1$ & $135(67.8)$ & $374(94.0)$ & 1 & 1 \\
\hline \multicolumn{5}{|l|}{ Abortion } \\
\hline No & $166(83.4)$ & $390(98.0)$ & 1 & 1 \\
\hline Yes & $33(16.6)$ & $8(2.0)$ & $9.691(4.383,21.428)^{* *}$ & $4.390(1.639,11.761) * *$ \\
\hline \multicolumn{5}{|c|}{ Multiplicity of pregnancy } \\
\hline Single & $181(91.0)$ & $384(96.5)$ & 1 & 1 \\
\hline Twin/Multiple & $18(9.0)$ & $14(3.5)$ & $2.728(1.327,5.606)^{* *}$ & $3.777(1.520,9.387) * *$ \\
\hline \multicolumn{5}{|l|}{ ANC follow up } \\
\hline No & $40(20.1)$ & $23(5.8)$ & $4.102(2.377,7.077) * *$ & $3.048(1.560,5.958) * *$ \\
\hline Yes & $159(79.9)$ & $375(94.2)$ & 1 & 1 \\
\hline \multicolumn{5}{|c|}{ Pre-existing hypertension } \\
\hline No & $164(82.4)$ & $383(96.2)$ & 1 & 1 \\
\hline Yes & 35 (17.6) & $15(3.8)$ & $5.449(2.897,10.251) * *$ & $3.805(1.687,8.581) * *$ \\
\hline \multicolumn{5}{|c|}{ Family history of hypertension } \\
\hline No & $137(68.8)$ & $373(93.7)$ & 1 & 1 \\
\hline Yes & $62(31.2)$ & $25(6.3)$ & $6.752(4.079,11.176) * *$ & $5.044(2.663,9.555) * *$ \\
\hline \multicolumn{5}{|c|}{ History of diabetes mellitus } \\
\hline No & $187(94.0)$ & $392(98.5)$ & 1 & 1 \\
\hline Yes & $12(6.0)$ & $6(1.5)$ & $4.193(1.550,11.343) * *$ & $5.032(1.594,15.891) * *$ \\
\hline
\end{tabular}

Differences in perinatal outcomes between women with and without HDP

There was low birth weight for $72(36.2 \%)$ cases and 15(3.8\%) controls (Fig. 2).

The difference of number of low birth weight between both groups was significant $\left(\chi^{2}(1, n=597)=\right.$ 123.76, $p=.000$, phi $=.46)$ (Table 6.)

\section{Discussion}

Risk factors of hypertension disorders during pregnancy

This study was conducted to identify the possible risk factors, maternal and perinatal outcomes of hypertensive disorders in pregnancy in Nekemte Referral Hospital, Ethiopia. The study revealed that the proportion of hypertensive disorders of pregnancy was $3.56 \%$, 
Table 5 Differences in Pregnancy outcomes between women with and without Hypertension disorders attended delivery services in the year July 2015-June 2017

\begin{tabular}{lllll}
\hline Variables & Case (\%) & Control (\%) & $X^{2}$ & $\mathrm{p}$ \\
\hline Onset of labor & & & & \\
Spontaneous & $88(44.2)$ & $345(87.9)$ & 123.50 & .000 \\
$\begin{array}{l}\text { Induced labor or c/s } \\
\text { Unspecified }\end{array}$ & $108(54.3)$ & $48(12.1)$ & & \\
Maternal death & $3(1.5)$ & $5(1.3)$ & & \\
No & & & & \\
Yes & $187(94.9)$ & $390(98.0)$ & 8.05 & .018 \\
Unspecified & $9(4.5)$ & $4(1.0)$ & & \\
Abruptio placenta & $3(1.5)$ & $4(1.0)$ & & \\
No & $177(88.9)$ & $388(97.5)$ & 28.91 & .000 \\
Yes & $19(9.5)$ & $3(0.8)$ & & \\
Unspecified & $3(1.5)$ & $7(1.8)$ & & \\
Preterm delivery & & & & \\
No & $117(58.8)$ & $386(96.9)$ & 154.24 & .000 \\
Yes & $80(41.2)$ & $8(2.0)$ & & \\
Unspecified & $2(1.0)$ & $4(1.0)$ & & \\
\hline
\end{tabular}

which was lower than the study conducted in Tikur Anbessa Hospital, Jimma University Specialized Hospital and Debre Berhan Referral Hospital [3, 5, 6, 10]. The reason might be due to the development of awareness creation made on controlling danger signs of maternal health by extension health workers in the current study than earlier study in a rural area.
Table 6 Different in perinatal outcome among women with Hypertension disorders of pregnancy

\begin{tabular}{lllll}
\hline Variables & Case & Control & $X^{2}$ & $p$ \\
\hline Low birth Weight & & & & \\
No & $121(60.0)$ & $382(96.0)$ & 123.76 & .000 \\
Yes & $72(36.2)$ & $15(3.8)$ & & \\
Unspecified & $6(3.0)$ & $1(0.3)$ & & \\
Stillbirth & & & & \\
No & $149(74.9)$ & $376(94.5)$ & 48.97 & .000 \\
Yes & $44(22.1)$ & $21(5.3)$ & & \\
Unspecified & $6(3.0)$ & $1(0.3)$ & & \\
Admission to NICU & & & & \\
No & $123(61.8)$ & $332(83.4)$ & 8.05 & .018 \\
Yes & $58(29.1)$ & $33(8.3)$ & & \\
Unspecified & $18(9.0)$ & $33(8.3)$ & & \\
\hline
\end{tabular}

This study showed that the extreme ages of reproductive years were found to be risk factors for hypertension during pregnancy with high incidence rates in old ages of greater than 35 years in comparison with the age range of 25-29 years. Concerning the current study, a hospital-based cross-sectional study conducted in Dassie Referral Hospital [11] and in Derashe, woreda [7] in Ethiopia reported that late age 30 years in some cases and age greater than 35 years in most cases were significantly associated with Hypertensive disorders of pregnancy.

About two folds of cases of HDP (64.8\%) were living in a rural area comparing to urban residence for this

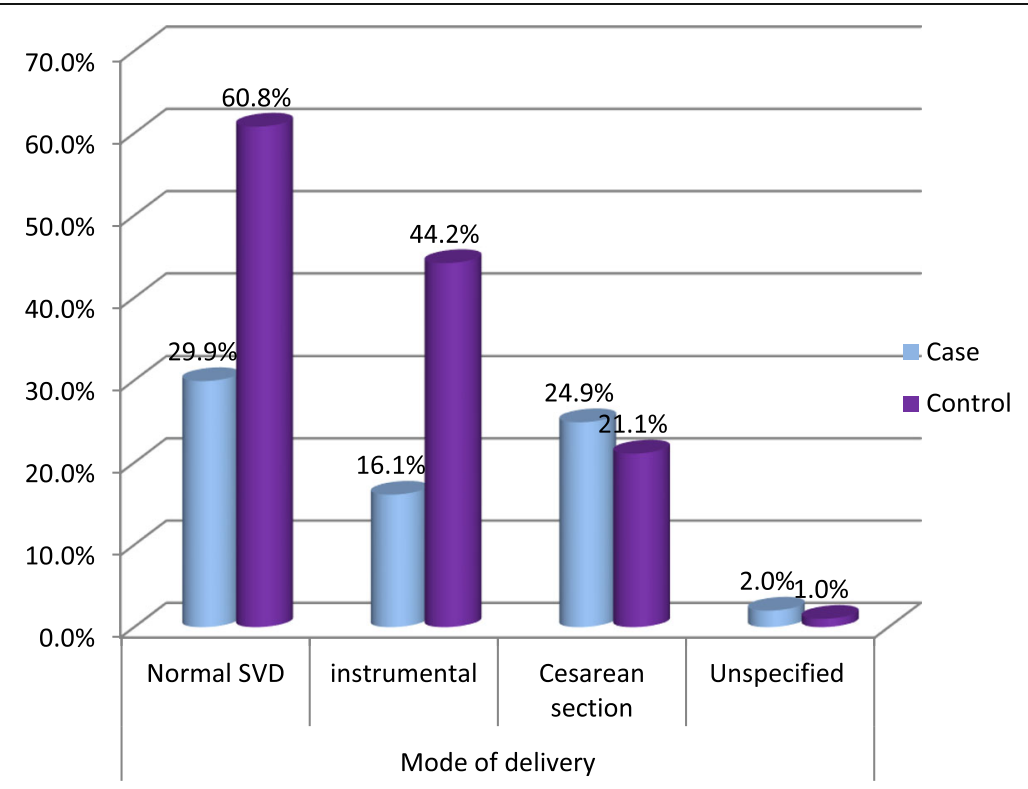

Fig. 2 Delivery modes for women with and without Hypertension disorders of pregnancy 
study. Then the rural residential area was found to be one of the risk factors of HDP.

This finding was similar to a study done in Jimma hospital of a similar country [5].

In the current study, those women with prim gravida pregnancies had 3.40 times higher odds of developing hypertension disorders as compared with their counterparts. Also, the occurrence of HDP was reported more serious in prim gravida mothers of case groups than the control group [12]. This is maybe because getting pregnancy for the first time likely induces psychological stress and physical boredom that make women at risk of the development of HDP.

In this study, women with previous abortions had 4.40 times higher odds of more likely to develop hypertensive disorders than with no previous abortion. Which is inconsistent with the current findings. For instance, a study conducted in Iran reported a noticeable effect of the history of abortion on increasing the risk of mild preeclampsia [13]. further noted that there was no significant difference in the incidence of preeclampsia between women with no history of previous abortion and term pregnancy and women who had previous preterm birth [14, 15].

This study indicated that twin pregnancies had more than three folds of developing hypertension during pregnancy as compared with having singleton pregnancies. This result is in line with the research conducted in Northeastern Ethiopia [11]. This study has shown that lack of antenatal care had more likely associated with hypertension disorder during pregnancy. A similar finding was found in Egypt [16] in which preeclampsia was higher in women who had not ANC follow up. This could be due to women who had ANC follow up might get preventive measures for preeclampsia from health care providers during their ANC follow up.

The present study revealed that the positive previous history of preeclampsia was significantly associated with the development of hypertension. Women who had pre-existing hypertension were more likely to develop hypertensive disorders compared to women who had a negative family history of hypertension.

This study coincides with the findings reported as women presenting preeclampsia/eclampsia constituted a high-risk group for developing long term chronic hypertension [17]. Besides, there is consensus in the literature regarding the role of the previous history of preeclampsia as a contributing factor for preeclampsia $[8,10,18]$.

In this study, a family history of hypertension had also a significant relationship with hypertensive disorders of pregnancy. Women who had a positive family history of hypertension were more likely to develop hypertensive disorders compared to women who had a negative family history of hypertension. More similar studies including in the Tigray region, Ethiopia revealed that a positive family history of chronic hypertension was a risk factor for HDP $[8,10,15,18-22]$.

From these findings, it seems that both maternal and fetal genes play a role in this syndrome. Therefore, for pregnant women with a family history of HDP, it should be monitored carefully both perinatally and in the postpartum period.

Another finding showed that gestational diabetes mellitus was significantly associated with hypertension disorders during pregnancy. It is supported by numerous studies that diabetes mellitus was considerable risk factors for the development of preeclampsia [10, 23-25].

In this study, diabetes Mellitus was found to be an important risk factor for developing HDP. It was 5.03 times higher for the positive history of diabetes mellitus. Thus, actions in public health focused to prevent these diseases are important to also prevent preeclampsia.

\section{Differences in pregnancy outcomes between women with and without HDP}

Cases and control of this study found to have significant differences in maternal and perinatal comes. Accordingly, induced labor or cesarean sections (CS) was significantly higher in cases $81(40.7 \%)$ than in controls $8(2.0 \%)$. Besides, data obtained on the mode of delivery show that Cesarean Section was higher in cases than in controls were as normal spontaneous vaginal delivery and instrumental deliveries were more common in controls than in cases.

The difference between the prevalence of abruption placenta complication between women with and without HDP was found to be significant.

The magnitude of the abruption placenta was more than three-fold in cases compared to in controls. Corresponding to this finding, it was reported that placental abruption was a common complication of mothers experiencing any type of hypertension during pregnancy $[26,27]$.

A considerable number of studies have reported that preterm birth was significantly higher in women with HDP than without. For instance, a study conducted in China indicated that $29.36 \%$ of women who had HDP gave birth before 37 weeks of gestation than $6.78 \%$ of women without HDP [26]. Besides, a study in Portugal showed a statistically significant association between preterm delivery and severity of HDP [28].

Of course, it is very important to conducted further studies with adequate samples in different parts of our country to determine the magnitude of difference that case and control groups have on giving preterm births.

A study conducted in Mettu Karl Referral Hospital reported that 120.37 perinatal mortality per 1000 deliveries, $10.2 \%$ stillbirth rate, $30.5 \%$ low birth weight, low 
18.5\% APGAR score and 31.4\% preterm delivery outcomes in women with HDP [29].

Besides Tesfaye A and Tilahun M. indicated $21.2 \%$ of infants of women with HDP were admitted in a neonatal intensive care unit [30].

Regarding pregnancy complications, among women with HDP in this study, 24.6, 9.5, 8.0, 3.5, and 3.5\% of them had developed complications of eclampsia, abruption placenta, DIC, acute renal failure, and pulmonary edema, respectively.

To this end, many studies reported similar findings $[1,6,31-33]$. The findings show that both maternal and fetal morbidity and mortality were higher in HDP. That is, maternal and perinatal complications women with HDP are common elsewhere in our world with a more severe rate in developing countries. Thus, improving antenatal care for pregnant mothers in our country is indispensable.

\section{Strength and limitation of the study Strength}

This study was done on the hypertensive disorders during pregnancy, which is one of the major maternal and perinatal cause of death. The use of a case-control study design helped to compare the effect of hypertension disorder between women with and without HDP.

\section{Limitation}

We utilized secondary data; which might be encountered to lack some of variables.

There were missed variables such as socio-demographic characteristic such as maternal education level, maternal weight, and height, smoking status of mothers.

\section{Conclusions and recommendations}

\section{Conclusion}

Women with hypertension during pregnancy have a greater risk of having adverse pregnancy outcomes as compared to normotensive pregnant women. Old age, rural residential area, being single, nulliparity, positive history of abortion, twin pregnancy, lack of ANC follows up, positive pre-existing hypertension, positive family history of hypertension and positive diabetes mellitus were identified as risk factors for developing hypertensive disorders of pregnancy.

\section{Recommendation}

Based on the findings the following recommendations were given.

Strengthening ANC service to strengthen counseling and managing the complication early.

Strengthening neonatal intensive care unit (including expansion) in health facilities could be an important input in reducing neonatal complications.

\section{Abbreviations}

ANC: Antenatal care; AOR: Adjusted odd ratio; C//S: Cesarean section; Cl: Confident Interval; DIC: Disseminated intravascular coagulopathy; HDP: Hypertension disorders during pregnancy; OR: Odd Ratio; SD: Standard Deviation

\section{Acknowledgments}

The researcher acknowledges to Wollega University, College of Health Science, Department of Midwifery, and Nekemte specialized Hospital card room, Obstetric, and Gynecologic Department for their support during data collection

\section{Declarations}

The content of the study is solely the responsibility of the authors.

\section{Authors' contributions}

LH wrote the proposal, participated in data collection, analyzed the data and drafted the paper. AT and NG approved the proposal with some revisions, participated in data analysis and revised subsequent drafts of the paper. All authors read and approved the final manuscript.

\section{Funding}

There are no sources of funding for this research. All costs were covered by researchers.

\section{Availability of data and materials}

The data sets used and analyzed during the current study are available from the corresponding author on reasonable request.

Ethics approval and consent to participate

Ethical clearance was obtained from Wollega University, College of health sciences, Institutional Health research ethics Review committee. Official letter was written to the Nekemte Specialized Hospital to get permission. Only official letter from Wollega University were written to administrative Hospital then administrative Hospital written to respective record office to get permission to collect the required data. Confidentiality was maintained by making the data collectors aware not to record any identification information found on the card including names.

\section{Consent for publication}

Not applicable.

\section{Competing interests}

"The authors declare that they have no competing interests".

\section{Author details}

'Department of Midwifery, Institute of Health Sciences, Wollega University, Nekemte, Ethiopia. ${ }^{2}$ Nekemte Referral Hospital, Oromia Regional National State, Nekemte, Ethiopia. ${ }^{3}$ Department of Midwifery, College of Medicine and Health Sciences, Wechamo University, Hossana, Ethiopia.

Received: 13 November 2019 Accepted: 20 December 2019 Published online: 06 January 2020

\section{References}

1. Institute of Health A. National Maternity Data Development Project 1 National Maternity Data Development Project: Hypertensive disorders during pregnancy Hypertensive disorders during pregnancy. 2014;1-9.

2. Queensland Clinical Guidelines. Hypertensive disorders of pregnancy. Queensland: Author; 2015.

3. Min Xue S, Graeme NS, Marc R, et al. Comparison of risk factors and outcomes of gestational hypertension and pre-eclampsia. PLoS One. 2017:1-13.

4. Gökhan Y, Kemal G, Halil A, Ahmet G, Mehmet B, Yavuz C. Comparison of perinatal and maternal outcomes of severe preeclampsia, eclampsia, and HELLP syndrome. J Turkish-German Gynecol Assoc. 2011 May;12:90-6.

5. Zenebe W, Hailemariam S, Mirkuzie W. Hypertension disorders of pregnancy in JUSH. Ethiop J Health Sci. 2011 Nov;21(3):15-25.

6. Wubanchi $T$, Yeneneh $G$, Abiy $H$, Miliard D, Damen $H$, Dereje $M$, et al. Patterns of hypertensive disorders of pregnancy and associated factors at 
Debre Berhan referral hospital, north Shoa, Amhara region. Ethiop Med J. 2015;2:57-65.

7. Genet A, Seblewengel L, Eskzyiaw A. Factors associated with hypertension during pregnancy in Derashie Woreda South Ethiopia. Insight Med Publishing Group. 2016 Sept;24(5):207-13.

8. Amal KS. Risk factors on hypertensive disorders among Jordanian pregnant women. Global J Health Sci. 2013;6(2):138-44.

9. Farha S, Ahmed J, Asma A, labal A, Safdar K. Anthropometric measurements as a risk for hypertensive disorders in pregnancy: A hospital-based study in the south Asian population. Department of Obstetrics \& gynecology, Pakistan. J Pak Med Assoc. 2011 Jan;61(1):58-63.

10. Samar E-N. Case-control study of risk factors associated with preeclampsia in the Gaza strip. J Med Med Sci. 2015 Dec;6(9):229-33.

11. Shamble W, Surender PR. Hypertensive disorders of pregnancy and associated factors among admitted pregnant cases in Dessie town referral hospital, north East Ethiopia, 2015. Med Res Chron. 2016 May;3(3):297-306.

12. Subburaman SV, Rajasekar S. An epidemiological study of assessment of fetal outcome in hypertensive disorders of pregnancy. Int J Med Pediatr Oncol, April-June, 2017:3(2):49-53.

13. Seyedeh HS, Manoush Z, Fariba M, Maryam A, Roya F, Seyedeh FDH, Fatemeh S. Comparison of preeclampsia risk factors regarding severity with control group. Zahedan J Res Med Sci. 2017 January;19(1):e5008.

14. Xu X, William DF, Nestor ND. History abortion, preterm, term birth and risk of preeclampsia: A population-based study. Am J Obstet Gynecol. 2002:187:1013-8.

15. Maimoona A, Rekha GD. Study of feto-maternal outcome in pregnancy induced hypertension. GJMR-E. 2014;14(1):20-5.

16. Essam A, El-Moselhy HOK, Soliman M, Amer Kl, Mohammad, Hani M, El-Aal A. Risk Factors and Impacts of Pre-Eclampsia: An Epidemiological Study among Pregnant Mothers in Cairo, Egypt. J Am Sci. 2011.

17. Olivier PM, Diallo C, Marcel TT, et al. A Study on Factors Related to Hypertensive Disorders in Pregnancy in Ngaoundere (Adamawa Region, Cameroon). Clin Med Res. 2016;Vol. 5(2):6-12. https://doi.org/10.11648/j.cmr. 20160502.11.

18. Duckitt $K$, Harrington D. Risk factors for pre-eclampsia antenatal booking: systematic review of controlled studies. BMJ. 2005;330(7491):565 [PMC free article] [PubMed].

19. Shoegaze M, Markos Y, Estifaons W, Taye I, Gemeda E, et al. Magnitude and Associated Factors of Preeclampsia Among Pregnant Women who Attend Antenatal Care Service in Public Health Institutions in Arba Minch Town, Southern Ethiopia. Gynecol Obstet (Sunnyvale). 2016;6(12):1-7. https://doi. org/10.4172/2161-0932.1000419.

20. Yohannes T, Semarya B, Alemseged A. Risk factors of pregnancy-related hypertension among women attending maternal health care service in selected public hospitals of Tigray, Ethiopia. Int J Dev Res. 2016 Aug;6(8):8904-11.

21. Larry J, Wisdom T, Wisdom KA, et al. Risk Factors Associated with Pregnancy Induced Hypertension in the Hohoe Municipality of Ghana. J Prev Med Health. 2017;1(3):1011.

22. Roberts CL, Ford JB, Algert CS, et al. Population-based trends in pregnancy hypertension and pre-eclampsia: an international comparative study. BMJ Open. 2011:1-9.

23. Caroline AD, Kátia GD, Mariana RBIR. Risk factors for hypertensive disorders of pregnancy in Southern Brazil. Rev Assoc Med Bras. 2011;57(6):678-82.

24. Hu R, Ying-Xue LI, Hai-hong DI, et al. Risk Factors of Hypertensive Disorders among Chinese Pregnant Women. J Huazhong Univ Sci Technol [Med Sci] 2015;35(6):801-7. https://doi.org/10.1007/s11596-015-1510-6.

25. Chris LB, George NI, Stephen JR, Cathy C. Association between gestational diabetes and pregnancy-induced hypertension. Am J Epidemiol. 2003:158:1148-53.

26. Chun Y, Yan R, Liying Z, Guanghui L, Changdong L, Yi C, et al. The 2011 survey on hypertensive disorders of pregnancy (HDP) in China: Prevalence, risk factors, complications, pregnancy, and perinatal outcomes. 2014 Jun;9(6):1-9.

27. Gulseren Y, Sabiha O, Harika B, Temel T, Eray C, Birol V, Aydın C. Materna and perinatal outcome in pregnancies complicated with hypertensive disorder of pregnancy: a seven-year experience of a tertiary care center. Arch Gynecol Obstet. 2005 Apr;273:43-9.

28. Povoa AM, Costa F, Rodrigues T, Patricio B. Prevalence of hypertension during pregnancy in Portugal: Hypertension pregnancy. Hypertension in Pregnancy. 2008;22(3):27984. https://doi.org/10.1080/10641950802000943.
29. Eshetu S, Mubarek A, Million T, Netsanet F. Maternal and fetal outcome of pregnancy-related hypertension in Mettu Karl referral hospital. Ethiop J Ovarian Res. 2015;8(10):1-7.

30. Tesfaye AG, Tilahun MR. Prevalence of Pregnancy Induced Hypertension and Its Bad Birth Outcome among Women Attending Delivery. Serv J Preg Child Health. 2017:4:5.

31. Nazli H, Nusrat S, Nazeer K, Sunita L, Nusrat H. Maternal and perinatal outcome of hypertensive disorders of pregnancy at a tertiary care hospital. J Dow Univ of Health Sci Karachi. 2011;5(1):12-6.

32. Laura A M, Anouk P, Michael H, Evelyne R, Peter v D. Diagnosis, evaluation, and management of the hypertensive disorders of pregnancy (review) Int J Women's Cardiovasc Health. 42014 Feb; 4:105-145.

33. Milano VL, Ota E, Ganchimeg T, Mori R, Souza JP. Risk factors of preEclampsia/Eclampsia and its adverse outcomes in low- and middle-income countries: a WHO secondary analysis. PLoS One. 2014;9(3):e91198.

\section{Publisher's Note}

Springer Nature remains neutral with regard to jurisdictional claims in published maps and institutional affiliations.

Ready to submit your research? Choose BMC and benefit from:

- fast, convenient online submission

- thorough peer review by experienced researchers in your field

- rapid publication on acceptance

- support for research data, including large and complex data types

- gold Open Access which fosters wider collaboration and increased citations

- maximum visibility for your research: over $100 \mathrm{M}$ website views per year

At BMC, research is always in progress.

Learn more biomedcentral.com/submissions 